\title{
EDUCAÇÃO ENTRE AS FRONTEIRAS DO DIREITO E DA CIDADANIA
}

\section{LA EDUCACIÓN POR ENTRE LA FRONTERA DEL DERECHO Y LA CIUDADANÍA}

Fabio Bezerra Correia Lima*

Resumo: Em 2015, no ápice do fluxo migratório, um quarto das pessoas que chegaram à União Europeia pleiteando refúgio eram crianças que procuravam guarida e melhores condições para o desenvolvimento de suas capacidades humanas. A pesquisa indagou se o ordenamento jurídico comunitário está preparado para garantir às crianças migrantes o acesso à educação - para que atinjam a plena capacidade cognitiva e possam desfrutar das melhores oportunidades de crescimento. A análise constatou garantias de acesso à educação de qualidade fixadas em normas vinculantes celebradas no âmbito da UE, prevendo que crianças refugiadas sejam amparadas desde a acolhida até a possível devolução ao país de origem. Por fim, percebeu-se que, mesmo de modo um pouco mais deficiente, o direito à educação também é assegurado às crianças em situação de irregularidade migratória.

Resumen: En 2015, en el ápice del flujo migratorio, una cuarta parte de las personas que llegaron a la Unión Europea pleiteando refugio eran niños que buscaban guarida y mejores condiciones para el desarrollo de sus capacidades humanas. La pesquisa investigó si el ordenamiento jurídico comunitario está preparado para garantizar a los niños migrantes el acceso a la educación, para que alcancen la plena capacidad cognitiva y puedan disfrutar de las mejores oportunidades de crecimiento. El análisis constató garantías de acceso a la educación de calidad fijadas en normas vinculantes celebradas en el marco de la UE, previendo que los niños refugiados sean amparados desde la acogida hasta la posible devolución al país de origen. Por último, se percibió que, aun de modo un poco más deficiente, el derecho a la educación también se asegura a los niños en situación de irregularidad migratoria.

Palavras-chave: Direito, Educação, Crianças, Migrantes, Comunitário Palabras clave: Derecho, Educación, Niños, Migrantes, Comunitario

*Universidade Federal da Paraíba, Brasil.
E-mail: fabiobclima@gmail.com
Recibido: 15/12/2017. Aceptado: 23/04/2018. 


\section{INTRODUÇÃO}

A diluição das fronteiras é consequência natural da atual configuração social global. O pós-modernismo introduziu a ideia de "modernidade líquida" sobre a qual Bauman ${ }^{1}$ discorre com maestria em seus estudos. Este arranjo social baseia-se no crescente sentimento de incerteza e ambivalência que permeia os indivíduos.

A liquidez se refere precisamente à capacidade de alteração dos estados sociais. O nomadismo passa a reger o contexto geral da humanidade líquida, que passa a fluir em sua própria vida, mudando de residências, trabalho, companheiros, valores. A fluidez do capital e dos conflitos ganham igual intensidade; percorrem o mundo e interferem no contexto local ao sabor das incertezas que os comandam.

Natural que, neste cenário de conflitos, incertezas, e dificuldades econômicas, os indivíduos migrem para onde possam obter melhores condições de vida. A globalização da informação tem se mostrado imprescindível na reunião das massas que fluem juntas para Europa.Zigmunt Bauman certamente não imaginou que a liquidez de sua modernidade seria interpretada de forma exponencialmente literal quanto esta.

As águas foram escolhidas como principal veículo para a viagem dos migrantes na busca desesperada por solo seguro. Aos indivíduos que rumam à Europa motivados por interesses meramente econômicos, associa-se um grande contingente de viajantes que procuram refúgio em função de guerras, conflitos e perseguições que assolam suas pátrias.

$\mathrm{O}$ ano de 2015 foi palco de um dos maiores movimentos migratórios das últimas décadas. $\mathrm{O}$ mundo acompanhou por jornais e mídias sociais o drama daqueles que, perseguidos em seus países de origem, se lançavam à sorte em pequenos botes infláveis abarrotados de pessoas. Sem qualquer condição de segurança, muitos acabaram não resistindo ao Mar Mediterrâneo.

Mais de 1 milhão de pessoas que lograram atravessar, depararam-se, no entanto, com outra leva de desafios. Quilômetros e mais quilômetros de estradas, cercas e enfrentamentos sociais. Neste coletivo encontramos também um considerável número de crianças e jovens que migram acompanhando os pais, outros que nascem no processo de migração e ainda alguns que empreendem a caminhada desacompanhados de qualquer adulto.

Nesse cenário, o Direito instigou a acolhida daqueles que procuravam guarida contra perseguições políticas, religiosas ou que fugiam de conflitos armados. No entanto, não tiveram a mesma recepção aqueles que migravam por meras razões econômicas.

A União Europeia (UE) está premida a agir, enquanto comunidade, para lidar com essa situação. Como explicado, a União possui a

1 BAUMAN, Z. Liquid Modernity. Cambridge: Polity, 2000. 
capacidade de legislar sobre determinadas matérias cuja competência lhe fora outorgada pelos Tratados originários. No que tange à migração, vê-se que não há envolvimento de um único país, mas de todos os que se encontram nesta zona de livre trânsito de recursos e pessoas.

Dessa forma, a melhor maneira de compreender o substrato da proteção do direito humano à educação de crianças migrantes na Europa não reside nas ordens nacionais, mas na estrutura legal comunitária. O Direito Comunitário, ou Direito da União Europeia, possui grande relevância, por constituir a fundação sobre a qual os Estados-membros elaborarão suas normas, orientando-os de forma fluida e contextualizada diante da constante adaptação social.

As normas comunitárias vinculantes assumem diversas formas e graus de aplicabilidade. As principais normas vinculantes da UE são os Tratados Originários, os Regulamentos, Diretivas e as Decisões. Tais instrumentos geram direito imediato para os indivíduos, por via da aplicabilidade direta, ou expectativa real de direito, mediante a obrigação gerada para os Estados legislarem sobre o tema, conforme as orientações da UE.

No entanto, mesmo sabendo que direitos verdadeiramente "palpáveis" surgirão dessas normas, é interessante que a análise não se resuma apenas a estas, visto que expressões não vinculantes dos órgãos comunitários - como as Recomendações - trazem importantes conceitos sobre os rumos que o bloco pretende assumir. Apenas assim será possível unir norma e valor, forma e matéria.

Nesta pesquisa, buscou-se compreender como as normas de direito comunitário produzidas pela União Europeia garantem o acesso à educação das crianças e jovens migrantes, considerando, principalmente, as particularidades dos que estão em maior condição de vulnerabilidade, quais sejam os asilados, os refugiados e os indocumentados.

Assim, importante que se evidenciem as normas que regem a política de asilo na União Europeia, os sujeitos que se beneficiam desta, e as garantias que lhes são postas durante o processo de asilo e após a concessão do status de refugiado.

\section{APÓS LONGA CAMINHADA, FINALMENTE O REFÚGIO. SERÁ?}

Salvaguardados os casos em que a migração é amparada por vistos e permissões de estadia prévias, os migrantes que enfrentam o caminho por medo de permanecerem em seus países de origem assim o fazem com a esperança de encontrar abrigo em novos territórios, sob a proteção de governos mais organizados.

A figura jurídica do asilo surge no direito internacional como a garantia de proteção aos indivíduos que sofrem perseguições ou grave 
ameaça ao bem-estar físico e moral, no território onde habitam. A Convenção dos Refugiados ${ }^{2}$ foi o primeiro instrumento internacional a definir a figura do refugiado.

Artigo 1 - (...) [qualquer pessoa] que tema ser perseguida por motivos de raça, religião, nacionalidade, grupo social ou opiniões políticas, se encontra fora do país de sua nacionalidade e que não pode ou, em virtude desse temor, não quer valer-se da proteção desse país, ou que, se não tem nacionalidade e se encontra fora do país no qual tinha sua residência habitual em consequência de tais acontecimentos, não pode ou, devido ao referido temor, não quer voltar a ele. (Grifos do autor).

Pensando em garantir uma proteção comum a todos estes indivíduos, a UE harmonizou os critérios para concessão do status de refugiado através do Sistema Europeu Comum de Asilo, operacionalizando-o através de algumas Diretivas, como a 2011/95/ $\mathrm{EU}^{3}$. Assim, estabelece-se, primeiramente, o conceito do refúgio e da proteção subsidiária.

É considerado refugiado um cidadão de um país terceiro ou apátrida que se encontre fora do seu país de origem e não queira ou não possa regressar a esse país por ter razões válidas para recear ser perseguido em virtude da sua raça, religião, nacionalidade, convicções políticas ou pertença a um determinado grupo social ${ }^{4}$.

Pessoa elegível para proteção subsidiária, é o nacional de um país terceiro ou um apátrida que não possa ser considerado refugiado, mas em relação ao qual se verificou existirem motivos significativos para acreditar que, caso volte para o seu país de origem ou, no caso de um apátrida, para o país em que tinha a sua residência habitual, correria um risco real de sofrer ofensa grave na acepção do artigo 15 , e ao qual não se aplique o artigo 17, n.1 e 2, e que não possa ou, em virtude dos referidos riscos, não queira pedir a proteção desse país ${ }^{5}$.

A partir dos excertos acima configura-se a noção de que o requerente de asilo $^{6}$ é a pessoa que peticiona a um Estado a proteção

2 ONU. Convenção sobre o Status de Refugiado. Nova Iorque: s.n, 1951.

3 CEU. Diretiva 2011/95/EU. Bruxelas: s.n, 2011.

4 CE. Compreender as políticas da União Europeia: Migração e Asilo. Bruxelas: s.n, 2014.

5 CEU. Diretiva 2011/95/EU. Op. cit.: Art. $2^{\circ}$, f.

6 No direito latino americano, contudo, a figura do asilo refere-se ao processo de proteção internacional dos perseguidos políticos. O art. 16 do Tratado de Direito Penal Internacional de Montevidéu, de 1889 , e o art. $2^{\circ}$ da Convenção sobre Asilo assinada na VI Conferência Pan-americana de Havana, em 1928, são claros ao determinar que o asilo é direcionado aos perseguidos por delitos políticos, sendo ato diplomático discricionário. Não se confunde, desta forma, com a figura do processo de asilo europeu, que é processo fundamentado e leva ao estatuto de refugiado. 
internacional e que, em sendo reconhecidos os requisitos para tal, o asilo é concedido alçando o indivíduo ao status de refugiado. Ademais, aqueles que não se enquadram como refugiado, porém encontram-se em risco real de violação de seus direitos em seu país de origem, são amparados sob o estatuto da proteção subsidiária.

$\mathrm{Na}$ União Europeia, o dever de amparar os indivíduos que se enquadram nesta situação está fundado na Convenção de Genebra de 1951, Carta de Direitos Fundamentais da União Europeia, no Tratado da União Europeia e no Tratado Sobre o Funcionamento da $\mathrm{UE}^{7}$ (CE, 2014).

Importante ressaltar que a Convenção de Genebra possui aplicabilidade em todos os Estados-membros da UE, visto que foi assinada e ratificada por todo o grupo. Da mesma forma a Carta de Direitos Fundamentais da União Europeia - $\mathrm{CDFUE}^{8}$ que preconiza o seguinte:

"O direito ao asilo deve ser garantido conforme as regras da Convenção de Genebra de 28 de julho de 1951 e Protocolo de 31 de Janeiro de 1967 que tratam do status de refugiado e de acordo com o Tratado da União Europeia e o Tratado de Funcionamento da União Europeia"”.

O artigo 19 do mesmo instrumento determina que o Estado destinatário do pedido de asilo não poderá repelir (expulsar) o requerente. Ainda, sob a redação do art. 78 do Tratado Sobre o Funcionamento da UE - TFUE ${ }^{10}$, a comunidade teria a obrigação de criar um Sistema Europeu Comum de Asilo (SECA) baseado nas obrigações assumidas pelos estados junto à Convenção de Genebra.

Foram criados inúmeros instrumentos legislativos com objetivo de implantar estas orientações. O sistema busca harmonizar procedimentos nacionais de concessão de asilo para que garantam segurança, equidade, eficácia e impeçam abusos dos requerentes, concedendo um status jurídico e fático adequado a qualquer nacional de um país terceiro que precise de proteção internacional ${ }^{11}$.

Àqueles que aguardam a decisão sobre o pedido de asilo devese assegurar condições de acolhimento satisfatórias a um nível de vida digno. De acordo com o Sistema Europeu Comum de Asilo, os Estadosmembros devem fornecer alojamento, vestimentas, alimentação, assistência médica, psicológica e educação aos requerentes menores de 18 anos. Também deve ser garantida a reunião familiar, a capacitação profissional e, de acordo com as limitações do Estado, acesso ao mercado de trabalho ${ }^{12}$.

7 CE. Compreender as políticas da União Europeia. Op. cit.

8 UE. Carta dos Direitos Fundamentais da União Europeia. 2012/C 326/02. Brussel: s.n., 2012. 9 Idem. Art.18.

10 UE.Consolidated version of the Treaty on European Union. 2008/C 115/01. Brussels: [s.n], 2007.

11 UE. Carta dos Direitos Fundamentais da União Europeia. Op. cit.

12 Ibidem. 
Dentro do Sistema Comum existem atualmente três Diretivas que abordam os Procedimentos para o Asilo (Diretiva 2013/32/EU) ${ }^{13}$, as Condições de Acolhimento (Diretiva 2013/33/EU) ${ }^{14}$ e o Status de Refugiado (Diretiva 2011/95/EU) ${ }^{15}$. Essas normas jurídicas de Direito Comunitário complementam os tratados vigentes, especificando e operacionalizando as garantias aos requerentes de asilo e refugiados.

A Diretiva 2013/32/EU é responsável por regulamentar todo o processo de apresentação do pedido de asilo - especialmente as instruções para formular a solicitação -, os critérios para análise do pedido e, por fim, as especificações sobre os benefícios garantidos aos requerentes. Com isso, busca assegurar que sejam tomadas decisões mais justas, rápidas e de melhor qualidade.

A Diretiva é clara em seus artigos $2^{\circ}, 7^{\circ}, 15$ e 25 ao afirmar que os requerentes em situação de vulnerabilidade, como os menores que estejam acompanhados ou não de responsáveis, terão assistência especial, voltada ao cumprimento de suas necessidades especiais.

A mesma norma ainda estabelece, em seu art. $9^{\circ}(1)$, proibição à expulsão dos requerentes de asilo enquanto a decisão sobre o pedido não for tomada. Dessa forma, consolida-se a ideia de que a presença do requerente de asilo no território da União Europeia é legal e gera para os Estados obrigações para com estes indivíduos no sentido de lhes garantir direitos básicos que componham um padrão digno de vida. Assim, veremos que o acesso à educação é fundamental ao desenvolvimento dos menores migrantes.

Com fulcro nessa assertiva, a União editou a Diretiva 2013/33/ EU objetivando assegurar condições de acolhimento dignas, enquanto os pedidos de asilo são processados. Entre as principais garantias destacam-se o acesso a alojamento, alimentação, saúde, emprego, cuidado psicológico e educação. Com isso, a norma procura garantir um tratamento humano e harmônico em toda a União Europeia.

Sendo garantido o asilo - seja mediante o status de refugiado conforme estipula o art. 13 da Diretiva 2011/95/EU, seja de pelo estatuto da proteção subsidiária estipulado no art. 18 da mesma Diretiva -, fica garantida a proteção internacional em sua máxima forma. Os sujeitos permanecem com os direitos que possuíam durante o pedido de asilo, porém agregam a autorização de residência com a devida documentação para viagens, bem como acesso às políticas de integração comunitária.

A Diretiva que garante Status de Refugiado (2011/95/EU) é imperiosa ao enunciar a importância de os Estados dedicarem atenção especial às crianças refugiadas. Desde o preâmbulo da Diretiva pode-se ver o zelo do legislador que dispõe sobre o tema. Observe-se a seguir:

13 Revogou a Diretiva 2005/85/CE.

14 Revogou a Diretiva 2003/9/CE.

15 Revogou a Diretiva 2004/83/CE. 
Diretiva 2011/95/EU - Preâmbulo

(18) O interesse superior da criança deverá ser uma das principais preocupações a ter em consideração pelos Estados-Membros na aplicação da presente Diretiva, em conformidade com a Convenção das Nações Unidas de 1989 sobre os Direitos da Criança.

(47) As necessidades específicas e as particularidades da situação dos beneficiários do estatuto de refugiado e do estatuto de proteção subsidiária deverão ser tidas em conta, na medida do possível, nos programas de integração que lhes são destinados, incluindo, se adequado, formação linguística e prestação de informação sobre os direitos e obrigações individuais relacionados com o seu estatuto de proteção no Estado-Membro em causa.

Ainda, deve-se considerar a presença de muitos que não se encontram em nenhuma das situações descritas acima. A presença de pessoas que entraram ou permanecem em um Estado sem a autorização ou justificativa legal é considerada irregular. A ilegalidade pode ser originada pela entrada clandestina no território, ou mesmo pelo fracasso na renovação da permissão de residência.

A política europeia tem se firmado na decisão de não permitir que estes indivíduos permaneçam no limbo existencial. De acordo com a Diretiva de Retorno $(2008 / 115 / \mathrm{EU})^{16}$ os Estados-membros vinculados por esta diretiva devem regularizar a residência destas pessoas ou emitir uma ordem de retorno aos seus países de origem.

No entanto, direitos assegurados pela $\mathrm{CDFUE}^{17}$, como o respeito pela vida privada e familiar dos indivíduos (art. $7^{\circ}$ ), podem se sobrepor à indicação de deportação, garantindo de forma circunstanciada e excepcional a manutenção do indivíduo em solo Comunitário. Como veremos adiante, a convivência familiar é base para o completo desenvolvimento educacional das crianças.

Assim, mesmo os menores em situação de irregularidade jurídica perante as normas migratórias da União Europeia encontrarão salvaguardados seus direitos humanos fundamentais. Para que seja possível o desenvolvimento de análise mais profunda sobre os instrumentos comunitários de garantia destes direitos, principalmente o direito de acesso à educação, primeiro é preciso adentrar no tema sob a ótica dos instrumentos internacionais de direito.

$\mathrm{O}$ direito à educação se entremeia com várias esferas do desenvolvimento humano, demandando a criação de um ambiente equilibrado e fundando-se no respeito a outros direitos fundamentais das crianças. Dessa forma, fundamental que as normas europeias de proteção às crianças migrantes pautem-se nestes quesitos para promoverem o pleno acesso à educação.

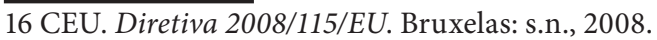

17 UE. Carta dos Direitos Fundamentais da União Europeia. Op. cit. 


\section{AS FUNDAÇÕES DO SISTEMA EUROPEU DE GARANTIA À EDUCAÇÃO}

A análise dos instrumentos de formação principiológica da ordem comunitária, ressalta a educação como direito de todos, desde os Tratados Fundantes, até a Carta de Direitos Fundamentais da União Europeia ${ }^{18}$.

$\mathrm{O}$ artigo $3^{\circ}$ do Tratado da União Europeia (TUE) ${ }^{19}$, tratado criador da UE, lança as bases para a conjugação das políticas de asilo e migração, sob a ótica do combate à exclusão e às discriminações, preservando a riqueza que flui da diversidade cultural. Esta expressão valorativa caminha na mesma direção daquilo que defende o artigo 26 da Declaração Universal dos Direitos Humanos (DUDH) ${ }^{20}$ e o artigo 13 do Pacto Internacional dos Direitos Econômicos, Sociais e Culturais $(\mathrm{PIDESC})^{21}$ para o exercício pleno do direito à educação.

O preâmbulo do TFUE, por sua vez, confirma a disposição dos Estados-membros a promoverem o desenvolvimento humano através do amplo acesso à educação e da contínua atualização dos conhecimentos dos povos que integram a comunidade. $\mathrm{O}$ art. $6^{\circ}$ do mesmo tratado garante à UE a competência para desenvolver ações de apoio, coordenação ou complementariedade aos Estados-membros na área de educação e formação ${ }^{22}$.

O European Network of Ombudspersons for Children - ENOC ${ }^{23}$ reconhece que, mesmo em épocas de crise econômica, as limitações impostas aos orçamentos públicos não podem servir de argumento para que os Estados deixem de cumprir suas obrigações internacionais para com as crianças, especialmente aquelas migrantes em estado especial de vulnerabilidade.

A Carta dos Direitos Fundamentais da União Europeia ${ }^{24}$ preleciona que o direito à educação pertence a todas as pessoas, e sua aplicação deve respeitar o direito à diversidade religiosa, filosófica e pedagógica.

A vedação à discriminação aparece no Art. 21 (2) da CDFUE, garantindo o acesso de todas as crianças aos meios educacionais sem que haja distinção por quaisquer fatores. Este dispositivo, de forma semelhante ao que estabelece a Convenção Contra Toda Forma de Discriminação em Educação (1960), diz ainda que a nacionalidade não

18 UE.Consolidated version of the Treaty on European Union. Op. cit.

19 Ibidem.

20 ONU. Declaração Universal dos Direitos Humanos. Nova Iorque: [s.n], 1948.

21 ONU. Pacto Internacional dos Direitos Econômicos, Sociais e Culturais. Nova Iorque: [s.n], 1966.

22 UE. Consolidated version of the Treaty on European Union. Op. cit.

23 ENOC. Position statement on "Children on the move". 17th Annual General Assembly. Brussels: 2013.

24 União Europeia. Carta dos Direitos Fundamentais da União Europeia. 2012/C 326/02. Brussels, 2012. 
pode ser critério impeditivo do pleno gozo deste direito.

Buscando satisfazer as necessidades dos migrantes em vulnerabilidade, especialmente aqueles irregulares, a Carta determina (art. 14) que toda criança nacional de país não-membro, exceto as que estão no bloco por curto período de tempo, são titulares do direito à educação básica. Inclui-se nessa conta aquelas que tiveram o processo de deportação adiado.

A preocupação da CDFUE coaduna com Princípio 10 da Declaração dos Direitos da Criança ${ }^{25}$, segundo o qual as crianças devem ser protegidas contra práticas discriminatórias. De modo similar, a Convenção das Nações Unidas sobre os Direitos da Criança - CDC ${ }^{26}$ prescreve em seu art. 22 que as crianças migrantes e refugiadas merecem cuidados especiais, por parte dos Estados, para que se integrem plenamente à sociedade e se desenvolvam segundo os parâmetros dos direitos aqui apresentados.

Maisalém, percebendoqueaUniãonecessitavadeumdirecionamento em suas políticas comunitárias de educação, principalmente no que interessava à inclusão eficaz dos migrantes ao sistema educacional, a Comissão Europeia ${ }^{27}$ apresentou o Green Paper - Migration \& Mobility: Challenges and Opportunities for EU Education Systems.

$\mathrm{O}$ comunicado da Comissão reconhece que as políticas educacionais na UE devem ser direcionadas a todas as crianças, inclusive as migrantes, independentemente de suas origens ou status de regularidade migratória. Em tom de recomendação não vinculante, ressalta ainda que é obrigação dos Estados destinarem atenção especial às crianças migrantes em condição socioeconômica debilitada.

$\mathrm{O}$ documento destaca que a significativa quantidade de alunos migrantes traz impactos consideráveis para os sistemas educativos. As escolas devem se ajustar para superarem os desafios particulares dos alunos, provendo uma educação equitativa de alta qualidade. Vê-se aqui o reconhecimento da necessidade de fortalecimento de um dos pilares do direito à educação: a solução equitativa das diferentes necessidades para que todos possam atingir níveis semelhantes de desenvolvimento ${ }^{28}$.

Mesmo sem caráter vinculante, o comunicado da Comissão traz reflexão interessante sobre o papel do acesso integral à educação como alicerce da vivência cidadã. Para a Comissão, o desafio educacional deve ser visto em um amplo contexto de coesão social - qualquer falha na plena integração das crianças migrantes nas escolas pode se transformar em um amplo fracasso de inclusão social.

25 ONU. Declaração Universal dos Direitos da Criança. Nova Iorque: s.n., 1959.

26 ONU. Convenção das Nações Unidas sobre os Direitos da Criança. Nova Iorque: s.n., 1989. 27 CE. Green Paper - Migration \& Mobility: Challenges and Opportunities for EU Education Systems. COM/2008/0423 final. Brussels: s.n., 2008.

28 Ibidem. 
De forma complementar o Conselho da União Europeia ${ }^{29}$ emitiu a Conclusão 2009/C 301/07, com o intuito de instruir os Estadosmembros, e a União como um todo, sobre a situação educacional das crianças com origem migrante. Esse documento considera documento que a realização plena do direito à educação é critério obrigatório para que a comunidade atinja elevado nível de coesão social.

Invocando a ideia de adaptabilidade dos sistemas educacionais, a Conclusão convida os Estados-membros a tomarem medidas adequadas para:

- A criação ou o reforço de mecanismos anti-discriminação, com o objetivo de promover a integração social e a cidadania ativa;

- A oferta de uma aprendizagem mais personalizada e de apoio individual, em particular para os filhos de migrantes que tenham fracos resultados escolares,

- A oferta de uma formação especializada para lidar com a diversidade linguística e cultural, bem como em competências interculturais, para os dirigentes escolares, os professores e o pessoal administrativo ${ }^{30}$.

Porfim, em 2012, o Conselho da Europa ${ }^{31}$ aprovou a Recomendação $\mathrm{CM} / \operatorname{Rec}(2012) 13$ a qual elencou os critérios a serem seguidos pelos Estados participantes (incluem todos os Estados-membros da UE) para a implementação de uma educação de qualidade.

Espelhando-se nas determinações globais expostas na CDC e na Carta Social da Europa, foi classificada como educação de qualidade aquela que garante acesso à aprendizagem a todos os alunos, particularmente àqueles em situação de vulnerabilidade, adaptando-se às suas necessidades específicas.

Visando promover a interdisciplinaridade, típica dos direitos humanos, a Recomendação considera ainda que a educação de qualidade deve promover a democracia, o respeito pelos direitos humanos e a justiça social; permitindo que as crianças desenvolvam competências voltadas à emancipação intelectual e tornem-se cidadãs responsáveis.

Assim também se posiciona o Conselho da União Europeia ${ }^{32}$ quando esclarece que a qualidade deve compreender não só o acesso ao sistema educativo, mas a garantia dos meios para que as atividades de aprendizagem satisfaçam as necessidades para o desenvolvimento do indivíduo de forma continuada. A longo prazo, significa garantir ao indivíduo ferramentas para renovação de suas competências, de modo

29 CEU. Council conclusions of 26 November 2009 on the education of children with a migrant background. 2009/C 301/07. Brussels: s.n., 2009.

30 Ibidem.

$31 \mathrm{CdE}$. Recommendation CM/Rec(2012)13 of the Committee of Ministers to member States on ensuring quality education. Strasbourg: s.n., 2012.

32 CEU. Diretiva 2013/33/EU. Op. cit. 
que desenvolva seu máximo potencial como cidadão.

Desse modo, vê-se que as normas comunitárias europeias reiteram a proteção aos direitos presentes na Convenção sobre os Direitos da Criança. A previsão do ensino gratuito é retratada como forma crucial para que se tenha uma educação disponível e acessível; e estas condições últimas são fundamentais para o pleno aproveitamento deste direito ${ }^{33}$.

Observe-se que nenhum dos instrumentos acima mencionados restringe os direitos educacionais a um grupo específico de nacionais, demonstrando sintonia das normas europeias com o princípio da não discriminação, fortemente difundido pela DUDH, PIDESC, CDC e CCTFDE.

No entanto, apesar de estabelecerem um cenário amplo de garantias para a educação de crianças migrantes, as normas até agora apresentadas carecem de ferramentas para a verdadeira operacionalização destas garantias no cotidiano dos Estados-membros. Para isso, a UE utilizouse de ferramentas de direito derivado, conforme será visto adiante.

\section{A CONCRETIZAÇÃO DA EDUCAÇÃO DE CRIANÇAS MIGRANTES ATRAVÉS DO DIREITO DERIVADO EUROPEU}

A beleza normativa do direito comunitário reside em sua capacidade única de mesclar a dinâmica internacional de resolução de problemas com a aplicabilidade e objetividade próprias dos sistemas nacionais. Isso se dá pelo grau de cooperação existente entre os Estadosmembros na formulação dos atos legislativos vinculantes (Regulamentos, Diretivas e Decisões).

Considerando o elevado percentual de migrantes requerentes de asilo, chegados à Europa em 2015 (e que continuam chegando até dias atuais), a primeira norma a ser considerada no âmbito do direito à educação das crianças migrantes é a Diretiva 2011/95/UE aprovada pelo Parlamento Europeu em conjunto com o Conselho da União Europeia ${ }^{34}$.

Essa Diretiva trata das condições para qualificação dos migrantes de países não membros, ou indivíduos apátridas, como beneficiários de proteção internacional - seja como refugiados ou sujeitos aptos à proteção subsidiária. Cabe relembrar que as Diretivas visam à unificação padronizada do direito entre os países do bloco, e assim o fazem encaminhando diretrizes aos Estados para que estes alterem seus ordenamentos nacionais (aplicabilidade indireta).

Desse modo, a Diretiva orientou os Estados a estabelecerem um estatuto uniforme para o tratamento de refugiados ou pessoas elegíveis

33 TOMASEVSKI, K. The State of the Right to Education Worldwide. Copenhagen: Free or Fee, 2006.

34 CEU. Diretiva 2011/95/EU. Op. cit. 
para proteção subsidiária, garantindo a estes últimos os mesmos direitos e benefícios aos quais tem acesso os primeiros.

No mesmo diapasão, a Diretiva 2011/95/UE, além de determinar critérios uniformes para identificação das pessoas que tenham necessidade de proteção internacional, estabeleceu um nível mínimo de benefícios à disposição desses sujeitos. Não poderia faltar no rol de garantias, em respeito ao art. 14 da $\mathrm{CDFUE}^{35}$, o direito à educação.

Considerando a indivisibilidade dos direitos humanos, a Diretiva 2011/95/UE determina que todos os direitos estipulados pela Convenção sobre os Direitos da Criança devem ser respeitos, garantindo o "interesse superior da criança" durante a aplicação de suas normas. Por conseguinte, procura fazer com que os Estados protejam a unidade familiar, requisito para o pleno desenvolvimento da educação.

Conforme mencionado no art 26 da DUDH $^{36}, 13$ do PIDESC $^{37} \mathrm{e}$ 28 da $\mathrm{CDC}^{38}$, a família desempenha papel importante na formação da criança. São os pais que criam a base valorativa e iniciam a sedimentação dos aspectos culturais na formação da criança. Agindo em parceira com a educação formal, a família torna-se instrumento condutor da política de formação.

Por essa razão, a Diretiva 2011/95/EU determina que os membros da família do beneficiário de proteção internacional que não possam, por si mesmos, se beneficiar desta proteção, possam reivindicar autorizações de residência. Tal determinação culmina por tratar com equidade o acesso à educação e o direito de conviver, visto que a separação familiar poderia criar déficits de aprendizagem e discriminação entre nacionais e migrantes ${ }^{39}$.

Adiante, em seu art. 27, a Diretiva 95 trata especificamente do acesso à educação, estipulando que os Estados-membros devem proporcionar aos menores, aos quais tenha sido concedida proteção internacional, pleno acesso ao sistema de ensino, nas mesmas condições que aos respectivos nacionais.

Essa determinação garante aos menores refugiados o acesso gratuito à educação de primeiro e segundo graus, do mesmo modo que é garantido aos nacionais pela Carta Social da Europa. Em sintonia com o Marco de Dakar ${ }^{40}$, a Diretiva ordena aos Estados que criem normas capazes de promover o acesso ininterrupto à educação, assegurando o pleno desenvolvimento dos menores.

35 UE, União Europeia. Carta dos Direitos Fundamentais da União Europeia. Op. cit. 36 ONU. Declaração Universal dos Direitos Humanos. Op. cit.

37 ONU. Pacto Internacional dos Direitos Econômicos, Sociais e Culturais. Op. cit.

38 ONU. Convenção das Nações Unidas sobre os Direitos da Criança. Op. cit.

39 UNESCO. Learning: the treasure within; report to UNESCO of the International Commission on Education for the Twentyfirst Century (highlights). Paris: UNESCO, 1996.

40 UNESCO. Marco de Acción de Dakar. Educación para Todos: cumplir nuestros compromisos comunes. Paris: s.n., 2000. 
Visando garantir um padrão mínimo de atendimento a todos os requerentes de proteção internacional, a União editou a Diretiva 2013/33/ $\mathrm{UE}^{41}$. O art. 14 da referida norma trata das condições segundo as quais será garantida a educação dos menores requerentes de proteção internacional.

Inicialmente, assegura-se o acesso ao sistema educacional, nos mesmos moldes dos menores nacionais, garantindo o ingresso do jovem no ensino secundário, mesmo que este tenha ultrapassado a maior idade. O parágrafo segundo do artigo supracitado estipula que o acesso à educação deve iniciar logo que apresentado o pedido, não podendo atrasar mais que três meses.

Interessante o que dispõe o mesmo artigo, um pouco mais adiante em sua redação, ao determinar que sejam realizados cursos preparatórios, especialmente quanto ao idioma, como forma de facilitar o acesso e a participação das crianças no sistema educacional.

A preocupação com a comunicação é primordial para que a criança possa compreender e assumir suas responsabilidades sociais em seu novo ambiente de convívio. Ao mesmo tempo, é peça chave para o respeito à nova cultura e para a manutenção dos costumes pátrios.

Em relatório sobre a igualdade de oportunidades entre jovens nacionais e migrantes, a $\mathrm{OECD}^{42}$ identificou que o rápido domínio do idioma local favorece a integração entre família e escola, fortalecendo o desenvolvimento da criança e ampliando as chances de empregabilidade futura dos jovens migrantes.

No tocante à essa questão, a Diretiva 2011/95/EU estabelece que, aos beneficiários do estatuto de refugiado e do estatuto de proteção subsidiária, deve ser garantida, na medida do possível, a participação em programas de integração, a formação linguística e a prestação de informações sobre os direitos e obrigações individuais relacionadas ao seu estatuto de proteção internacional.

Ressalta-se aqui a convergência das Diretivas com as diretrizes da $\mathrm{UNESCO}^{43}$, segundos as quais a educação deve garantir aos indivíduos a capacidade de conhecer e fazer. Com a quebra da barreira linguística, abrem-se novas oportunidades de aprendizagem, reduzindo o gap potencial entre migrantes e nacionais. Apostar no idioma é, dessa forma, investir na educação equitativa.

Noutro aspecto, além do idioma, há que se garantir a participação da família no processo de educação para que o desenvolvimento da criança atinja seu pleno potencial. Assim é que o art. 23 da Diretiva 2011/95/EU e o art. 12 da Diretiva 2013/33/EU trazem salvaguardas extras à proteção da unidade familiar.

41 CEU. Diretiva 2013/33/EU. Bruxelas: s.n., 2013a.

42 OECD. Organization for Economic Co-Operation and Development. Equal Opportunities? The labor market integration of the children of immigrants. Paris: OECD Publishing, 2010.

43 UNESCO. Learning: the treasure within. Op. cit. 
Ambos os dispositivos requerem que, nos casos em que o Estado seja o responsável por garantir a moradia dos migrantes refugiados, todos os membros do núcleo familiar sejam alocados no mesmo território. No que tange aos menores desacompanhados, criou-se a preocupação de alocá-los com parentes residentes no país ou famílias adotivas, tamanha a importância dessa convivência ${ }^{44}$.

A atuação harmônica entre a família e a escola permite ao jovem integrar-se na comunidade, por esforços próprios, e também através dos vínculos nutridos por todos os parentes. Por meio desta participação, cria-se o respeito mútuo e o senso de responsabilidade, inerentes à manutenção da paz social e da convivência igualitária.

Novamente, observa-se que as normas comunitárias de direcionamento legislativo se aproximam das lições de Jacques Delors. Ao integrar a família e estimular a participação ativa do menor na comunidade, o direito à educação garante também o direito à convivência e à autonomia do $\operatorname{ser}^{45}$.

Importante mencionar que, tanto a Diretiva 2011/95/UE quanto a 2013/33/UE, foram devidamente incorporadas aos ordenamentos jurídicos dos Estados-membros através da edição de normas nacionais pautadas nos direcionamentos estipulados pelo Parlamento Europeu nos textos das Diretivas.

Outra norma importante que deve ser mencionada é o Regulamento (UE) n. 1288/2013 ${ }^{46}$, que criou o Programa "Erasmust" para o ensino, a formação, a juventude e o esporte. Apesar de tratar da educação de forma geral, e direcionada principalmente aos nacionais de países membros, o Regulamento também trata do ensino de crianças e jovens migrantes.

A norma, editada em 2013, estabelece um cenário de fortalecimento das políticas educacionais na União Europeia no qual exista melhoria contínua no acesso às oportunidades de aprendizagem de crianças migrantes. Para tanto, ressalta a importância da cooperação entre escolas e mobilidade de profissionais da educação.

Com o intuito de melhorar a qualidade da educação escolar - através do desenvolvimento de competências, da equidade e da inclusão nos sistemas educacionais -, o Regulamento determina que os Estados elaborem estratégias para redução da evasão escolar, melhoria de habilidades básicas e maior participação dos jovens nas decisões públicas $^{47,48}$.

As políticas de garantia de acesso e de qualidade da educação

44 CEU. Diretiva 2013/33/EU. Op. cit.

45 UNESCO. Learning: the treasure within. Op. cit.

46 CEU. Regulamento (UE) 1288/2013. Bruxelas: s.n, 2013b.

47 Ibidem.

48 UNESCO, Educación de calidad para todos: um assunto de derechos humanos. Santiago: Oreacl, 2008. 
estipuladas pelo Regulamento, destinadas à educação para o conhecer e o ser, são consideradas de aplicabilidade direta. Isso significa que o direito nasce para os indivíduos a partir da edição do Regulamento, podendo ser exigido dos Estados que o respeitem, mesmo que não exista norma compatível no ordenamento jurídico nacional ${ }^{49,50,51}$.

Reconhecendo a força conferida ao Regulamento e preocupados com a operacionalização do acesso de migrantes à educação, a União editou o Regulamento (UE) n. 516/2014 ${ }^{52}$ que criou o Fundo para o Asilo, a Migração e a Integração. Esta norma procura estruturar o acesso material dos migrantes aos direitos que lhes são assegurados. Considerese o primeiro item das considerações preambulares do Regulamento $516 / 2014$.

(1) O objetivo da União de criar um espaço de liberdade, segurança $e$ justiça deverá ser alcançado, nomeadamente, através de medidas comuns que configurem uma política de asilo e de imigração baseada na solidariedade entre os Estados-Membros, que seja equitativa para com países terceiros e os seus nacionais. O Conselho Europeu de 2 de dezembro de 2009 reconheceu que os recursos financeiros a nível da União se deverão tornar cada vez mais flexíveis e coerentes, em termos de alcance e de aplicabilidade, de forma a apoiar o desenvolvimento da política em matéria de asilo e migração ${ }^{53}$.

A criação de um fundo comum foi uma estratégia para garantir o padrão na operação acolhimento e de asilo, em todos os países membros da União. Dessa forma, fica mais fácil assegurar que todos terão acesso aos direitos previstos nas normas comunitárias e internacionais.

Neste aspecto, o art. $5^{\circ}$ do Regulamento 516/2014 direciona os recursos do Fundo à prestação de ajuda material ou serviços de apoio que facilitem o acesso à educação às pessoas que pleiteiam o status de refugiado ou de proteção subsidiária.

Conforme 0 art. $9^{\circ}$ do Regulamento, o Fundo também deve apoiar ações estratégicas que visem atender às necessidades de integração dos nacionais de países terceiros a nível local e/ou regional. Dentre as medidas amparadas estão aquelas centradas na "educação e formação, incluindo a formação linguística e ações preparatórias que facilitem o acesso ao mercado de trabalho" ${ }^{\text {. }}$.

49 CRAIG, P.; DE BURCA, G. EU Law: Text Cases and Materials. Fifth Edition. Oxford: OUP Oxford, 2011.

50 MAZZUOLI, Valério de Oliveira. Curso de direitos humanos. 2 ed. Rio de Janeiro: Forense; São Paulo: Método, 2015.

51 UNESCO. Learning: the treasure within. Op. cit.

52 CEU. Regulamento (UE) n. 516/2014. Bruxelas: s.n., 2014b.

53 Ibidem.

54 Ibidem. 
O viés da adaptabilidade educacional defendido por Tomasevski ${ }^{55}$ é latente nesta norma comunitária. O legislador demonstrou a clara preocupação em moldar as políticas públicas às necessidades específicas das crianças migrantes, garantindo-lhes não só a perspectiva formal, mas instrumentos materiais de acesso à educação de qualidade, à participação plena (por intermédio do domínio do idioma local) e à capacidade de aprender para transformar o seu ser.

Por fim, merece destaque a Diretiva 2008/115/EU ${ }^{56}$ que versa sobre padrões e procedimentos comuns aos Estados-membros para o retorno de nacionais de países terceiros que estejam indocumentados. Os dispositivos da norma demonstram o valor atribuído à educação pelos Estados-membros da UE. Mesmo nos casos de ilegalidade migratória comprovada, o acesso das crianças ao sistema educativo é garantido.

$\mathrm{O}$ art. 14 esclarece que certos princípios devem ser assegurados aos indivíduos que estejam pendentes de retorno ao país de origem, por causas de imigração ilegal. Dentre as garantias elencadas, encontra-se o direito de os menores acessarem o sistema de educação básica até o momento da concretização do retorno ao seu país.

Outra situação que merece ênfase é o direito de menores detidos usufruírem de atividades de lazer e recreativas e, a depender da duração da detenção, terem acesso à educação formal. Assim sendo, a diretiva consagra formalmente o princípio da não discriminação e da universalidade do direito à educação.

Este aglomerado de normas comunitárias, regionais e internacionais delineia, de forma entremeada, as fronteiras entre o direito e a cidadania das crianças migrantes. Pode-se observar o crescente movimento de universalização do direito que, nas últimas décadas, ampliou a quantidade de indivíduos sob sua tutela.

As normas produzidas no seio da União Europeia, com objetivo de regulamentar o acesso à educação de crianças migrantes, refletem os debates internacionais sobre o tema. Ficou claro que a universalidade, característica básica dos Direitos Humanos, é componente integrante dos Tratados europeus e das normas derivadas que tratam da educação de crianças migrantes.

Isto posto, as normas de direito comunitário têm progredido para uma abordagem cada vez mais inclusiva. Os grupos vulneráveis, como as menores migrantes e suas famílias, têm obtido o reconhecimento do direito à educação mesmo quando se encontram em situação de irregularidade migratória.

A fronteira entre direito e cidadania ainda é visível para estas pessoas, porém, ao contrário das fronteiras geográficas que estão constantemente sendo reforçadas por cercas e muros, os direitos parecem

55 TOMASEVSKI, K. The State of the Right to Education Worldwide. Op. cit. 56 CEU. Diretiva 2008/115/EU. Op. cit. 
crescer e criar pontes para que as crianças migrem da marginalização para a plena vivência da cidadania.

\section{CONSIDERAÇÕES FINAIS}

A imersão na realidade migratória, vivida pela União Europeia nos últimos anos, revelou a dimensão do desafio enfrentado pelos Estados-membros para o acolhimento e garantia dos direitos desses novos habitantes. Os dados das agências imigratórias apresentam um número de 1.35 milhões de pedidos de asilo no ano de 2015 .

Conclui-se que esse volume, per se, demanda da comunidade uma nova estratégia de ação, visto que no ano anterior as solicitações de asilo não chegaram nem à metade desse montante. No entanto, o processamento dos pedidos de asilo e o reconhecimento do status de refugiado não esgotam em si mesmos a demanda sobre os Estados. É necessário que todos os que chegam tenham reconhecidos e garantidos os seus direitos como humanos.

Dentro do pool de migrantes encontram-se não só os requerentes de asilo - que representaram em média 85\% dos migrantes de 2015 -, mas também aqueles que migram legalmente por razões econômicas, ou que tentam a sorte sem o amparo da autorização oficial para migração.

Parte considerável desse coletivo é composto por crianças. Chegando à razão de um quarto do total de migrantes, os menores possuem vulnerabilidade ainda maior que o restante do grupo, visto que estão mais sujeitos às violações de seus direitos quando se encontram em ambiente distinto daquele onde inicialmente viviam sua infância.

Diante de tantos desafios para a inclusão social destas crianças, a educação aparece como poderosa ferramenta transformadora, capaz de alavancar o desenvolvimento destes indivíduos. Como direito humano, a educação deve ser considerada a partir de um contexto de respeito a todas as outras garantias, aplicando-se os princípios da indivisibilidade e interdependência dos direitos.

Reconhecida como direito básico, gratuito e universal pela Declaração Universal dos Direitos Humanos, Pacto Internacional dos Direitos Econômicos, Sociais e Culturais e Convenção da ONU sobre os Direitos da Criança, a educação deve valorizar a relação família-criança, preparando o menor para a autonomia intelectual, pautando-se sempre nos ideais de paz, tolerância, liberdade e solidariedade.

A educação é reconhecida como ferramenta humanizadora que possibilita à criança aprender a conviver, a fazer, a conhecer e a ser. Através de um sistema não discriminatório de educação para todos, constrói-se não só um crescimento econômico e social equilibrado, mas a própria identidade comunitária.

Para tanto, é preciso que à todas as crianças migrantes sejam 
garantidos: o pleno acesso, gratuito e universal; condições materiais de usufruto da aprendizagem; qualidade no ensino, através do respeito à identidade cultural, línguas e valores do país de acolhimento e de origem; inclusão da família; e, por fim, equidade de tratamento, para que todos atinjam um patamar semelhantes de oportunidades para o desenvolvimento.

As Diretivas 2011/95/EU, 2013/33/EU e 2008/115/EU; todas amparadas no que prevê a Convenção de Genebra de 1951 e na Carta de Direitos Fundamentais da União Europeia são claras quanto à necessidade de assistência especial aos menores migrantes, estejam eles acompanhados ou não de responsáveis. A acolhida deve respeitar ainda o princípio da não expulsão imediata e garantir o acesso a direitos básicos para a manutenção de um padrão digno de vida.

Objetivando assegurar condições de acolhimento dignas, a Diretiva 2013/33/EU elenca alguns cuidados a serem tomados enquanto os pedidos de asilo são processados. Entre as principais garantias destacam-se o acesso a alojamento, alimentação, saúde, emprego, cuidado psicológico e educação. Com isso, a norma procura firmar um tratamento humano e harmônico em toda a UE.

Por sua vez, o art. 27 da Diretiva 2011/95/EU trata especificamente do acesso à educação, estipulando que os Estados-membros devem proporcionar aos menores, aos quais tenha sido concedida proteção internacional, pleno acesso ao sistema de ensino, nas mesmas condições que aos respectivos nacionais.

Já em relação aos migrantes em irregularidade documental, nos casos em que não conseguem regularizar sua presença, mesmo sendo encaminhados para a deportação continuam sendo detentores de alguns direitos básicos. Dentre as garantias elencadas pela diretiva 2008/115/ EU encontra-se o direito de os menores acessarem o sistema de educação básica até o momento da concretização do retorno ao seu país.

De modo geral, observa-se que o grupo de migrantes amparados pelo status de refugiado, ou em processo de reconhecimento do asilo, possuem garantias bem definidas quanto ao seu direito de pleno acesso ao sistema educativo, incluindo a previsão de uma educação de qualidade, integrativa e moldada para o desenvolvimento de oportunidades futuras.

Por outro lado, os menores que se encontram em situação de imigração irregular não possuem garantias tão explicitas no ordenamento jurídico comunitário. Afora a Diretiva 2008/115/EU, o direito à educação destes jovens pende das normas internacionais ou regionais de direitos humanos.

$\mathrm{Na}$ esfera internacional a DUDH, CDC e PIDESC evidenciam a educação como direito de todas as crianças, sem distinção de nacionalidade ou quaisquer outras características discriminatórias. No âmbito da Europa, os Tratados Fundantes (TUE e TFUE) e a Convenção 
Europeia para os Direitos Humanos também elencam a educação como direito universal, gratuito e atemporal.

Deste modo, fica claro que as crianças em situação de irregularidade migratória também são detentoras do direito à educação, na mesma abrangência que todas as outras - sejam nacionais dos Estados-membros ou qualificadas como refugiados. No entanto, por não estarem acobertadas por normas operacionais de direito derivado, na mesma intensidade que as refugiadas, terminam sem receber uma proteção eficiente e eficaz.

Apesar destas restrições, ao analisarmos a totalidade do sistema de proteção do direito humano à educação das crianças migrantes, podemos concluir que as garantias formais estão consolidadas em um vasto espectro normativo. Espera-se, com isso, que o direito possa liderar as transformações sociais a partir da alteração das políticas públicas.

Assim, a fronteira geográfica, muitas vezes atroz com os migrantes, vai dando espaço à fronteira do Direito. Esta, muito mais permissível que aquela, aos poucos tem conseguido assegurar um "dever ser" mais justo e humanizado. Aos poucos, a ideia de que os direitos humanos devem ser garantidos a todos, estejam ou não em seu país de origem, vai se sedimentando, possibilitando a verdadeira vivência dos princípios da universalidade e não-discriminação.

Por fim, sabendo que a prática tende a apresentar variações daquilo que o mundo jurídico prevê, sugere-se que esta linha de investigação se expanda, adotando linhas de pesquisa aplicada para que se evidencie qual o grau de aplicação destas normas nos Estados da UE.

\section{REFERÊNCIAS BIBLIOGRÁFICAS}

BAUMAN, Z. Liquid Modernity. Cambridge: Polity, 2000.

CDE. Recommendation CM/Rec(2012)13 of the Committee of Ministers to member States on ensuring quality education. Strasbourg: s.n., 2012.

CE. Compreender as políticas da União Europeia: Migração e Asilo. Bruxelas: s.n, 2014.

CEU. Council conclusions of 26 November 2009 on the education of children with a migrant background. 2009/C 301/07. Brussels: s.n., 2009.

CEU. Diretiva 2008/115/EU. Bruxelas: s.n., 2008.

CEU. Diretiva 2011/95/EU. Bruxelas: s.n, 2011.

CEU. Regulamento (UE) 1288/2013. Bruxelas: s.n, 2013.

CEU. Regulamento (UE) n. 516/2014. Bruxelas: s.n., 2014. 
CRAIG, P.; DE BURCA, G. EU Law: Text Cases and Materials. Fifth Edition. Oxford: OUP Oxford, 2011.

ENOC. Position statement on "Children on the move". 17 th Annual General Assembly. Brussels: 2013.

MAZZUOLI, Valério de Oliveira. Curso de direitos humanos. 2 ed. Rio de Janeiro: Forense; São Paulo: Método, 2015.

OECD. Organization for Economic Co-Operation and Development. Equal Opportunities? The labor market integration of the children of immigrants. Paris: OECD Publishing, 2010.

ONU. Convenção das Nações Unidas sobre os Direitos da Criança. Nova Iorque: s.n., 1989.

ONU. Convenção sobre o Status de Refugiado. Nova Iorque: s.n, 1951.

ONU. Declaração Universal dos Direitos da Criança. Nova Iorque: s.n., 1959.

TOMASEVSKI, K. The State of the Right to Education Worldwide. Copenhagen: Free or Fee, 2006.

UE. Carta dos Direitos Fundamentais da União Europeia. 2012/C 326/02. Brussel: s.n., 2012.

UNESCO, Educación de calidad para todos: um assunto de derechos humanos. Santiago: Oreacl, 2008.

UNESCO. Learning: the treasure within; report to UNESCO of the International Commission on Education for the Twenty $\neg$ first Century (highlights). Paris: UNESCO, 1996.

UNESCO. Marco de Acción de Dakar. Educación para Todos: cumplir nuestros compromisos comunes. Paris: s.n., 2000.

UNIÃO EUROPEIA. Carta dos Direitos Fundamentais da União Europeia. 2012/C 326/02. Brussels, 2012.

\section{RESUMO BIOGRÁFICO}

Fabio Bezerra Correia Lima é Mestrado em Avaliação e Gestão do Desenvolvimento - IOB / University of Antwerp. Bacharel em Direito pela UFPB - Brasil. Bacharel em Administração de Empresas pela UFPB - Brasil. Alumnus Business Consultancy International FHWN - Áustria. 